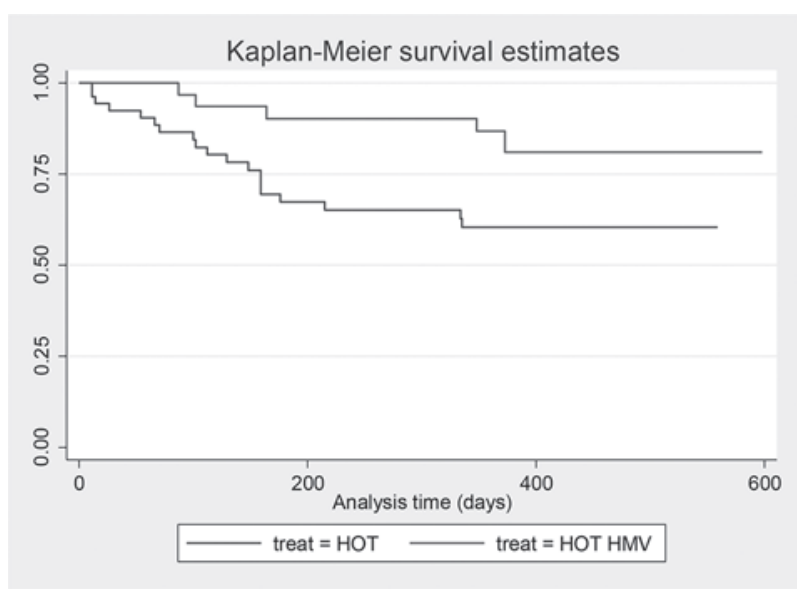

Abstract S37 Figure 1 Kaplan-Meier plot showing survival from randomisation to end of trial follow up by treatment arm. Adjusted for number of COPD admissions in previous year, prior use of long term oxygen therapy (LTOT), age and BMI.

[JAMA;317:2177]. Delivery of HMV is essential and a perprotocol analysis was conducted to assess if patients who were adherent had better outcome.

Method Patients were randomised to HOT or HOT-HMV if they had persistent hypercapnia $\left(\mathrm{PaCO}_{2}>7 \mathrm{kPa}\right) 2$ weeks following resolution of respiratory acidosis ( $\mathrm{pH}>7.30)$ secondary to an acute exacerbation of COPD. NIV was titrated to nocturnal hypoventilation and patients were followed up for 1 year. Patients allocated to the HOT arm that breached safety criteria had HMV added to HOT. Patients were included in the analysis in the HOT-HMV group if they had mean adherence of $>4$ hours/night. Patients allocated to HOT were included up until trial withdrawal or treatment switching.

Results 57 patients were randomised to HOT-HMV of whom 15 were non-adherent and 11 had missing usage data and were treated as non-adherent. 59 patients were allocated to HOT of whom 5 patients were excluded due to treatment switching. Median time to readmission or death was 1.1 months in the HOT group and 3.7 months in the HOT-HMV group (adjusted hazard ratio (HR) 0.41 , 95\% CI 0.23, 0.74, $\mathrm{p}=<0.01)$. All-cause mortality was reduced in the HOT-HMV group (figure 1 ; adjusted $\mathrm{HR} \quad 0.36$, 95\% CI 0.13, 0.97, $\mathrm{p}=0.04)$. There was a significant treatment effect on $\mathrm{PaCO}_{2}$ at 6 weeks $\left(\Delta \mathrm{pCO}_{2}-0.9 \mathrm{kPa}, \mathrm{p}<0.01\right)$ which was observed at 12 months $\left(\mathrm{pCO}_{2}-0.7 \mathrm{kPa}, \mathrm{p}=0.04\right)$ with no significant effect on health related quality of life at 6 weeks (SRI $\mathrm{p}=0.28$, SGRQ $\mathrm{p}=0.98$ ) or 12 months (SRI $\mathrm{p}=0.71$, SGRQ $\mathrm{p}=0.31$ ).

Conclusion Patients with persistent hypercapnia following an acute exacerbation of COPD who were adherent to HOTHMV had a reduced risk of readmission or death and in addition, unlike the intention to treat analysis, had an improvement in gas exchange and a reduction in all-cause mortality at 12 months. Addition of HMV to HOT should be considered for patients with persistent hypercapnia following a life-threatening exacerbation of COPD.

\section{S38 HOME MECHANICAL VENTILATION (HMV) AND HOME OXYGEN THERAPY (HOT) FOLLOWING AN ACUTE EXACERBATION OF COPD IN PATIENTS WITH PERSISTENT HYPERCAPNIA: PREDICTING 1 YEAR ADMISSION-FREE SURVIVAL IN THE HOT-HMV UK TRIAL}

${ }^{1} \mathrm{~PB}$ Murphy, ${ }^{1} \mathrm{G}$ Arbane, ${ }^{2} \mathrm{~A}$ Bisquera, ${ }^{1} \mathrm{~N}$ Hart. 'Guy's and St Thomas' NHS Foundation Trust, London, UK; ${ }^{2}$ King's College London, London, UK

\subsection{6/thoraxjnl-2017-210983.44}

Introduction Data from the HOT-HMV UK trial showed an improvement in admission-free survival with the addition of home mechanical non-invasive ventilation (HMV) to home oxygen therapy (HOT) in patients with persistent hypercapnia following an acute exacerbation of COPD [JAMA;317:2177]. A post-hoc analysis was conducted to investigate (1) which baseline patient characteristics predict 12 month outcome and (2) the difference of these characteristics between treatment groups.

Abstract S38 Table 1 Comparison of baseline variables between patients with favourable (no readmission and alive at 12 months) to those with poor (readmission or death within 12 months)

\begin{tabular}{|c|c|c|c|c|c|c|c|}
\hline & \multicolumn{3}{|c|}{ Home NIV and home oxygen } & \multicolumn{3}{|l|}{ Home oxygen } & \multirow{2}{*}{$\begin{array}{l}\text { Between treatment } \\
\text { group comparison }\end{array}$} \\
\hline & $\begin{array}{l}\text { No admission/death } \\
(n=20)\end{array}$ & $\begin{array}{l}\text { Admission/death } \\
(n=37)\end{array}$ & p-value & $\begin{array}{l}\text { No admission/death } \\
(\mathrm{n}=17)\end{array}$ & $\begin{array}{l}\text { Admission/death } \\
(n=42)\end{array}$ & $p$-value & \\
\hline Age (mean (sd)) & $66.95(9.67)$ & $65.84(10.50)$ & 0.696 & $66.53(9.42)$ & $67.31(8.97)$ & 0.767 & 0.6242 \\
\hline $\mathrm{FEV}_{1}$ (mean (sd)) & $0.66(0.24)$ & $0.54(0.20)$ & 0.042 & $0.63(0.30)$ & $0.52(0.19)$ & 0.123 & 0.6784 \\
\hline $\mathrm{ABG}$ on air $\mathrm{pCO}_{2}$ (mean $\left.(\mathrm{sd})\right)$ & $7.72(0.96)$ & $7.94(0.81)$ & 0.358 & $7.88(0.99)$ & $7.88(0.89)$ & 0.992 & 0.4998 \\
\hline $\mathrm{ABG}$ on air $\mathrm{pO}_{2}$ (mean (sd)) & $6.49(1.12)$ & $6.40(1.21)$ & 0.788 & $6.31(1.15)$ & $6.41(1.13)$ & 0.764 & 0.6802 \\
\hline Weight (mean (sd)) & $61.24(13.49)$ & $60.84(15.69)$ & 0.925 & $69.28(16.55)$ & $60.20(17.49)$ & 0.072 & 0.2752 \\
\hline BMI (mean (sd)) & $22.23(4.52)$ & $22.27(4.88)$ & 0.974 & $25.09(5.10)$ & $21.79(5.76)$ & 0.044 & 0.1864 \\
\hline FFM (mean (sd)) & $32.09(6.53)$ & $30.05(5.90)$ & 0.266 & $31.20(6.06)$ & $29.95(5.56)$ & 0.482 & 0.8213 \\
\hline SRI.SS (mean (sd)) & $47.02(15.16)$ & $45.16(15.07)$ & 0.665 & $44.46(17.08)$ & $47.86(15.09)$ & 0.464 & 0.3996 \\
\hline SGRQ.SS (mean (sd)) & $68.84(17.56)$ & 73.55 (12.69) & 0.259 & $71.09(15.65)$ & $68.22(12.39)$ & 0.467 & 0.1967 \\
\hline SGRQ.SX (mean (sd)) & $69.42(18.45)$ & $69.00(16.87)$ & 0.933 & $74.94(15.45)$ & $71.89(16.81)$ & 0.531 & 0.6762 \\
\hline SGRQ.AC (mean (sd)) & $85.20(12.77)$ & $92.02(7.48)$ & 0.015 & 88.14 (13.38) & $84.96(14.03)$ & 0.438 & 0.0261 \\
\hline SGRQ.IM (mean (sd)) & $59.28(23.14)$ & $64.41(18.93)$ & 0.381 & $58.04(20.49)$ & $57.67(16.62)$ & 0.943 & 0.5342 \\
\hline MRC (mean (sd)) & $4.05(1.18)$ & $4.78(0.48)$ & 0.002 & $4.19(0.98)$ & $4.51(0.78)$ & 0.194 & 0.2314 \\
\hline
\end{tabular}

$\mathrm{ABG}$, arterial blood gas; $\mathrm{BMI}$, body mass index; $\mathrm{FEV}_{1}$, forced expiratory volume in $1 \mathrm{~s}$; FFM, fat free mass; MRC, medical research council dyspnoea score; $\mathrm{pCO}_{2}$, partial pressure of carbon dioxide in arterial blood; $\mathrm{pO}_{2}$, partial pressure of oxygen with arterial blood; SRI-SS, severe respiratory insufficiency questionnaire summary score; SGRQ-SS, St George's respiratory questionnaire summary score. 
Method Patients were randomised to HOT or HOT-HMV if they had persistent hypercapnia $\left(\mathrm{PaCO}_{2}>7 \mathrm{kPa}\right) 2$ weeks following resolution of respiratory acidosis $(\mathrm{pH}>7.30)$ secondary to an acute exacerbation of COPD. Non-invasive ventilation was titrated to treat nocturnal hypoventilation and patients were followed up for 1 years after discharge. Between group comparison of readmission and death were assessed in terms of baseline demographics, anthropometrics, lung function, gas exchange, quality of life and dyspnoea level.

Results 116 patients were enrolled and randomised to HOT $(n=59)$ or HOT-HMV $(n=57)$ with (mean \pm sd or median [IQR]) age $67 \pm 10$ years, BMI 22 [18-26] $\mathrm{kg} / \mathrm{m}^{2}, \mathrm{FEV}_{1} 0.6$ $\pm 0.2 \mathrm{~L}, \mathrm{PaCO}_{2} 59 \pm 7 \mathrm{mmHg}$, SRI-SS 46 \pm 15 , SGRQ-SS 74 [63-80], MRC dyspnoea score 5 [4-5]. Patients allocated HOT were less likely to be admitted with increasing BMI (25 \pm 5 vs $\left.22 \pm 6 \mathrm{~kg} / \mathrm{m}^{2} ; \mathrm{p}=0.044\right)$. Patients allocated to HOTHMV are were less likely to be admitted if they had higher $\mathrm{FEV}_{1}(0.66 \pm 0.24$ vs $0.54 \pm 0.20 \mathrm{~L} ; \mathrm{p}=0.042)$, lower levels of dyspnoea (MRC dyspnoea score $4 \pm 1.0$ vs $5 \pm 0.5 ; \mathrm{p}=0.002$ ) or higher levels of specific measures of quality of life (SGRQAC $85 \pm 13$ vs $92 \pm 7 ; p=0.015$ ) (Table 1 ). Baseline severity of respiratory failure did not predict 12 month outcome in either group.

Conclusion Factors influencing outcome in patients with COPD and persistent hypercapnia receiving HOT-HMV treatment were airways obstruction and level of dyspnoea. However, in the patients receiving HOT alone, BMI was the only factor. There was no between group difference in with the exception of a sub-scale of the SGRQ. Interestingly, the severity of respiratory failure at baseline does not influence risk of readmission or death within 12 months as the patients all demonstrated severe chronic respiratory failure

\section{S39 AN OUTREACH SERVICE FOR DOMICILIARY NON- INVASIVE VENTILATION (NIV) IMPROVES ACCESS FOR PATIENTS}

${ }^{1}$ SK Mansell, ${ }^{1} \mathrm{~S}$ Cutts, ${ }^{2} \mathrm{R}$ Kanakaraj, ${ }^{3} \mathrm{R}$ Jose, ${ }^{4} \mathrm{~A}$ Mackay, ${ }^{3} \mathrm{I}$ Moonsie, ${ }^{1} \mathrm{~S}$ Mandal. ${ }^{1}$ Royal Free London NHS Foundation Trust, London, UK; ${ }^{2}$ Whittington Hospital NHS Trust, London, UK; ${ }^{3}$ North Middlesex University Hospital NHS Trust, London, UK; ${ }^{4}$ University College London Hospital NHS Foundation Trust, London, UK

\subsection{6/thoraxjnl-2017-210983.45}

Introduction and Objectives Hypercapnic ventilatory failure is common and patients often present to hospital with decompensation. As well as requiring acute non-invasive ventilation (NIV), patients may require domiciliary NIV (D-NIV). Traditionally, inpatients requiring D-NIV awaited transfer to a hospital with a D-NIV service. Long wait times for transfer could result in; repeated decompensations, D-NIV services appearing inaccessible and alternative sub-optimal treatment options being considered. Increasing healthcare pressures mean newer models of care need to be considered to avoid delayed treatment. In May 2014 our D-NIV service implemented an outreach function. Inpatients referred for D-NIV were either visited at their base hospital, or attended as a day-case at our centre. Patients were assessed and, if appropriate, commenced on D-NIV. This study assessed the impact of our outreach service on accessibility to D-NIV services, hospital length of stay (LoS) and 90 day readmission rates (90R).

Methods Data were collected retrospectively pre-outreach and prospectively post-outreach service. Diagnosis, LoS and 90R were collected for all patients referred for D-NIV from five referring hospitals between January 2008 and April 2017. Historic patient databases of patients receiving acute NIV at site A were searched to compare pre-outreach to post-outreach service D-NIV referral rates. Based upon current evidence based practice, case note review of the historic database was undertaken to identify patients eligible for consideration of DNIV, but who were not referred.

Results Table 1. Demonstrates the impact of the outreach service. The study demonstrates a significant increase in referral rates following implementation of the outreach service. A clinically important reduction (21 days) in average LoS and subsequent decrease in bed day costs was observed. The average LoS cost per patient requiring D-NIV establishment pre-outreach was $£ 19,600$, compared to $£ 11200$ post-outreach service. A non-significant increase in $90 \mathrm{R}$ was observed.

Conclusion An outreach service appears to improve referral rates for D-NIV. There was a trend towards reduced LoS, potentially saving $£ 8400$ per patient. Factors contributing to increased 90R warrant further investigation. Our D-NIV outreach service appears to be an effective model of care, which has significantly increased patient accessibility to D-NIV and could be easily implemented in other services.

Abstract S39 Table 1 Referral rates, hospital LoS and 90 day readmission rates pre and post D-NIV outreach service

$\begin{array}{lll}\begin{array}{l}\text { Pre-outreach } \\ \text { service }\end{array} & \begin{array}{l}\text { Post- } \\ \text { outreach } \\ \text { service }\end{array} & \\ & \end{array}$

Patients eligible for D-NIV

Referral rates per acute NIV episodes at one referring site (Site A) (\%)

Further patients eligible for

consideration of D-NIV at Site A but

not referred (\%) COPD

COPD/OSA

$\mathrm{OHS}$

NMD

$10 / 669(1.5 \%) \quad 31 / 350$

$p<0.001$

$84 / 659(9.8 \%) \quad 1 / 319$

$\mathrm{p}<0.001$

$58.3 \%(49) \quad(0.3 \%)$

$4.7 \%(4) \quad 100 \%$

$30.9 \%(26) \quad$ (n1)

CWD

Patients at site A-E referred to D-NIV

service (n) Diagnosis\%(n): COPD

COPD/OSA

NMD

OHS

CWD

Other

$1.1 \%(1)$

$4.7 \%(4)$

$\begin{array}{ll}\begin{array}{l}\text { Inpatient } \\ \text { referral } \mathrm{n}=11\end{array} & \begin{array}{l}\text { Inpatient } \\ \text { referral }\end{array} \\ \text { Outpatient } & \mathrm{p}=0.431 \\ \text { referral } \mathrm{n}=7 & 26.4 \% \\ \text { Total } \mathrm{n}=17 & (18) \\ 38.9 \%(7) & 10.2 \%(7) \\ 0 \%(0) & 7.4 \%(5) \\ 16.7 \%(3) & 47 \%(32) \\ 38.9 \%(7) & 5.9 \%(4) \\ 5.6 \%(1) & 2.9 \%(2) \\ 0 \%(0) & \end{array}$

Patients referred to the service

$\begin{array}{lrl}\begin{array}{l}\text { Pre- } \\ \text { outreach } \\ \text { service }\end{array} & \begin{array}{l}\text { Post- } \\ \text { outreach }\end{array} & \\ \text { service } & \\ \begin{array}{l}\text { Site A-E } \\ \mathrm{n}=11\end{array} & \begin{array}{r}\text { Sites A-E } \\ \mathrm{n}=68\end{array} & \text { Mean diff } 20.7 \\ 49(49) & 28(26) & \begin{array}{l}(95 \% \mathrm{Cl}-14 \text { to } 56) \\ \mathrm{p}=0.167\end{array} \\ 10 \% & 30 \% & \mathrm{p}=0.264\end{array}$

$\mathrm{COPD}=$ chronic obstructive pulmonary disease, $\mathrm{OSA}=$ obstructive sleep apnoea, $\mathrm{NMD}=$ neuromuscular disease, $\mathrm{OHS}=$ obesity hypoventilation syndrome $\mathrm{CWD}=$ chest wall deformity. 